\title{
Transient Optoelectronic Analysis of the Impact of Material Energetics and Recombination Kinetics on the Open-Circuit Voltage of Hybrid Perovskite Solar Cells
}

\author{
Scot Wheeler, ${ }^{\dagger, \ddagger(0)}$ Daniel Bryant, ${ }^{\dagger}$ Joel Troughton, ${ }^{\S}$ Thomas Kirchartz, ${ }^{\|, \perp \odot 0 ~}$ Trystan Watson, ${ }^{\S}$
} Jenny Nelson, ${ }^{\ddagger}$ and James R. Durrant* ${ }^{*},, \S_{(0)}$

${ }^{\dagger}$ Department of Chemistry and ${ }^{\star}$ Department of Physics, Imperial College London, South Kensington Campus, London SW7 2AZ, United Kingdom

${ }^{\S}$ SPECIFIC IKC, College of Engineering, Swansea University, Swansea SA1 8EN, United Kingdom

"IEK5-Photovoltaics, Forschungszentrum Jülich, 52425 Jülich, Germany

${ }^{\perp}$ Faculty of Engineering and CENIDE, University of Duisburg-Essen, Carl-Benz-Strasse 199, 47057 Duisburg, Germany

\section{Supporting Information}

ABSTRACT: Transient optoelectronic measurements were used to evaluate the factors determining the open-circuit voltage of a series of planar photovoltaic devices based on hybrid perovskite layers with varying iodine/bromine ratios. Employing differential charging and transient photovoltage measurements, we used a simple device model based on the charge-carrier-density dependence of nongeminate recombination to re-create correctly not only the measured device open-circuit voltage $\left(V_{\mathrm{OC}}\right)$ as a function of light intensity but also its dependence on bromine substitution. The $173( \pm 7) \mathrm{mV}$ increase in device voltage observed with $20 \%$ bromine substitution is shown to result from a $227( \pm 8) \mathrm{mV}$ increase in effective electronic band gap, which was offset in part by a $56( \pm 5) \mathrm{mV}$ voltage loss due to faster carrier recombination. The faster recombination following $20 \%$ bromine substitution can be avoided by indene $-\mathrm{C}_{60}$ bisadduct (ICBA) substitution into the $[6,6]$-phenyl- $\mathrm{C}_{61}$ butyric acid methyl ester (PCBM) electron-collection layer, resulting in a further $73( \pm 7)$

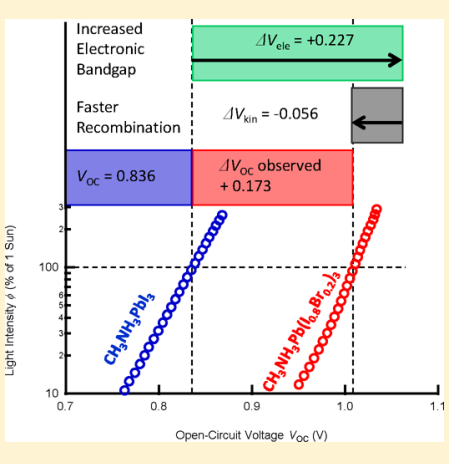
$\mathrm{mV}$ increase in device $V_{\mathrm{OC}}$. These results are consistent with surface recombination losses at the perovskite/fullerene interface being the primary limitation on the $V_{\mathrm{OC}}$ output of bromine-substituted devices. This study thus presents, and experimentally validates, a simple model for the device physics underlying voltage generation in such perovskite-based solar cells and demonstrates that this approach can provide key insights into factors limiting this voltage output as a function of material energetics.

\section{INTRODUCTION}

Organic-inorganic lead halide perovskites are attracting extensive interest for photovoltaic device applications. Rapid progress has been made in device efficiencies, with several recent studies reporting solar power conversion efficiencies exceeding $20 \%$ for devices based on the $\mathrm{ABX}_{3}$ perovskite structure, ${ }^{1,2}$ with methylammonium lead halide (MAPX) being the most well-known. ${ }^{3,4}$ Such promising device efficiencies are motivating studies of the materials and device physics underlying device function. One important performance parameter determining photovoltaic device efficiency is the open-circuit voltage, $V_{\mathrm{OC}}$. Indeed, the remarkably high $V_{\mathrm{OC}}$ values achieved for MAPX-based devices, approaching to within $0.4 \mathrm{~V}$ of the MAPX optical band gap, are a key factor behind their high device efficiencies. ${ }^{5-7}$ However, at present, there is no consensus on how photovoltage generation in perovskite devices depends on variations in material composition and device architecture. Several studies have provided evidence that the energetics of both the perovskite active layer ${ }^{8,9}$ and the electrodes $^{5,10}$ are the important factors determining $V_{\mathrm{OC}}$. It has also been reported that methylammonium lead iodide (MAPI) materials can exhibit remarkably long charge-carrier lifetimes in films (given their high carrier mobilities), ${ }^{11-14}$ although the relevance of these long carrier lifetimes to achieving high device voltages is not as well-established. Herein, we report a transient optoelectronic analysis of a series of planar junction perovskite solar cells. The approach assesses the impacts of both kinetics and energetics on device voltage. Employing a simple device model, we demonstrate that, by using these transient measurements, it is possible to successfully rationalize not only the absolute device open-circuit voltage $V_{\mathrm{OC}}$ but also its variation with light intensity and perovskite-layer halide substitution.

Charge extraction (CE), small-perturbation transient photocurrent (TPC), and small-perturbation transient photovoltage (TPV) have been shown to be powerful in situ probes of

Received: March 14, 2017

Revised: May 10, 2017

Published: June 6, 2017 
charge-carrier accumulation and recombination and have been employed to demonstrate how changes in material energetics and charge-carrier recombination dynamics impact cell voltage in both organic and dye-sensitized solar cells. ${ }^{15-17}$ Although such transient optoelectronic measurements have previously been used to probe perovskite solar cells, ${ }^{18-22}$ the validity of this approach to understanding and reconstructing perovskite solar cell performance is yet to be demonstrated, due in part to the presence of hysteresis phenomena in the devices studied to date, which complicates both data measurement and analysis. ${ }^{23}$ The planar hybrid organic-inorganic perovskite device structure utilizing the common organic interlayers poly $(3,4-$ ethylenedioxythiophene):poly(styrene sulfonate) (PEDOT:PSS) and [6,6]-phenyl- $\mathrm{C}_{61}$-butyric acid methyl ester (PCBM) is of interest to many because of the potential for lowcost, low-temperature solution processability with the added benefit of significantly reduced hysteresis. ${ }^{24-26}$ This reduced hysteresis, combined with a respectable photovoltaic performance and stability, makes these planar perovskite solar cells an ideal foundation for a detailed optoelectronic analysis of the materials and device physics underlying photovoltage generation in perovskite solar cells.

As an example system, we investigate the effect of exchanging iodide bromide in planar devices made from the $\mathrm{CH}_{3} \mathrm{NH}_{3} \mathrm{~Pb}$ $\left(\mathrm{I}_{1-x} \mathrm{Br}_{x}\right)_{3}$ (MAPX) perovskite system. Bromide addition results in an increase in material band gap within a limited $\mathrm{Br}$ range and has been shown to lead to higher $V_{\mathrm{OC}}$ values. $^{7-9,27-30}$ $\mathrm{CH}_{3} \mathrm{NH}_{3} \mathrm{~Pb}\left(\mathrm{I}_{1-x} \mathrm{Br}_{x}\right)_{3}$ therefore represents an example of a material series where the voltage appears to be determined, at least in part, by the perovskite energetics. We also investigate the effect of partially substituting $\mathrm{PCBM}$ with indene $-\mathrm{C}_{60}$ bisadduct (ICBA) in the electron-collection layer to raise the energetics of this layer and, thereby, to investigate the role of Fermi-level pinning in such bromine-substituted devices. The first aim of this work was to investigate whether the transient optoelectronic techniques discussed above can be used to recreate correctly the open-circuit voltage of a planar MAPI solar cell and its dependence on light intensity, thereby testing a simple kinetic model of $V_{\mathrm{OC}}$. Our second aim was to investigate whether this approach is able to quantify the contributions from materials energetics and from charge recombination dynamics to the observed variation in device $V_{\mathrm{OC}}$ with bromine and ICBA substitution.

\section{EXPERIMENTAL SECTION}

2.1. Fabrication. Cells were fabricated using a previously reported procedure. ${ }^{31}$ Indium tin oxide- (ITO-) coated glass substrates were coated with a PEDOT:PSS layer (P VP AL 4083, Heraeus) at $3500 \mathrm{rpm}$ for $45 \mathrm{~s}$ and then subjected to annealing at $150{ }^{\circ} \mathrm{C}$ for $10 \mathrm{~min}$. Stock perovskite precursor solutions of $\mathrm{CH}_{3} \mathrm{NH}_{3} \mathrm{PbI}_{3}$ and $\mathrm{CH}_{3} \mathrm{NH}_{3} \mathrm{PbBr}_{3}$ were prepared by dissolving stoichiometric ratios of $\mathrm{PbX}_{2}$ and $\mathrm{CH}_{3} \mathrm{NH}_{3} \mathrm{X}(\mathrm{X}=$ $\mathrm{I}, \mathrm{Br}$ ) in a mixture of dimethyl sulfoxide (DMSO) and $\gamma$ butyrolactone (GBL) (7:3) at $1.25 \mathrm{M}$ and stirring for $10 \mathrm{~min}$. To obtain the bromide containing perovskites, the stock solutions of $\mathrm{CH}_{3} \mathrm{NH}_{3} \mathrm{PbI}_{3}$ and $\mathrm{CH}_{3} \mathrm{NH}_{3} \mathrm{PbBr}_{3}$ were combined in volumetric ratios of $0.9: 0.1$ and $0.8: 0.2$, respectively. Perovskite precursor solution was coated in a nitrogenenvironment glovebox by a spin-coating procedure using two speeds, with toluene being dripped onto the surface during the second step. This was followed by drying at $100{ }^{\circ} \mathrm{C}$ postdeposition for $10 \mathrm{~min}$. A $[6,6]$-phenyl- $\mathrm{C}_{61}$-butyric acid methyl ester (PCBM) (Solenne) layer was deposited by spin coating of an $18 \mathrm{mg} / \mathrm{mL}$ solution in chlorobenzene at $1000 \mathrm{rpm}$ for $1 \mathrm{~min}$. For ICBA:PCBM layers, a solution of indene $-\mathrm{C}_{60}$ bisadduct (ICBA) (Solenne) was made by dissolving the solid in chlorobenzene at a concentration of $18 \mathrm{mg} / \mathrm{mL}$. This solution was then added to the PCBM solution at a ratio of 20:80, after which the mixture was deposited by spin coating at $1000 \mathrm{rpm}$ for $1 \mathrm{~min}$. The cells were contacted by sequentially evaporating a Ca layer $(5 \mathrm{~nm})$ and an $\mathrm{Al}$ layer $(150 \mathrm{~nm})$, leaving an active area of $0.045 \mathrm{~cm}^{2}$. The devices were then encapsulated using a glass coverslip and a UV-curable epoxy sealant (Ossila) for further testing.

2.2. J-V/EQE Measurements. Current density-voltage $(J-V)$ characteristics were measured using a xenon lamp at AM1.5 solar illumination (Oriel Instruments) calibrated to a KG5 silicon reference cell with a Keithley 2400 source meter at a scan speed of $0.125 \mathrm{~V} / \mathrm{s}$.

External quantum efficiency (EQE) measurements were performed using a PV Measurements QEX10 system. Spectral response was measured between 300 and $850 \mathrm{~nm}$ in dc mode with a step size of $10 \mathrm{~nm}$ and calibrated using a silicon reference photodiode.

2.3. Transient Measurements. Transient photocurrent (TPC) and transient photovoltage (TPV) measurements and analysis were carried out as previously reported. ${ }^{32}$ To briefly summarize, background illumination was provided by a ring of 12 white light-emitting diodes (LEDs) capable of a power of up to 4 sun equivalents, calibrated to the short-circuit current density $\left(J_{\mathrm{SC}}\right)$ as measured under simulated AM1.5 illumination. Any changes in background illumination or bias conditions were followed by a wait time greater than $2 \mathrm{~s}$ before measurements commenced to avoid effects of hysteresis as a result of these conditions. Although still expected, the hysteresis equilibrates considerably faster than for the architecture investigated. $^{24}$ During TPV measurements, the device was held at a range of open-circuit conditions utilizing the $1 \mathrm{M} \Omega$ input impedance of a Tektronix TDS3032 oscilloscope and controlled by the background illumination. Following a small optical excitation provided by a pulsed Continuum Minilite $\mathrm{Nd}$ :YAG laser at $532 \mathrm{~nm}$ with a pulse width of $<10 \mathrm{~ns}$, the resulting small-perturbation voltage transient decay, measured on the oscilloscope, was fitted with a monoexponential to obtain the small-perturbation carrier lifetime. The intensity of the small optical excitation, which remained constant under all background illumination conditions, was set to achieve a voltage perturbation of less than $20 \mathrm{mV}$ at 1-sun background illumination to operate within the small-perturbation regime; however, the perturbation also had to be large enough to be distinguished at higher light intensities (as the voltage deflection decreased at higher density of state population). During TPC measurements, the device was held close to shortcircuit conditions with a $50 \Omega$ measurement resistance. The resulting current transient from the same excitation as for TPV measurements was integrated to obtain an estimate of the number of carriers generated by the laser excitation. A value for the total charge $Q$ at low background light intensity $(<20 \%$ sun) was used for differential charging analysis to avoid nonlinear recombination losses at short circuit that could be present at high light intensities. Key assumptions of TPC/TPV measurements require the extra charge to equilibrate with the device electrodes prior to recombination and generation to be independent of applied field between short circuit and open circuit in high-permittivity materials. Fitting of the experimental data was typically done at light intensities greater than $10 \%$ of 

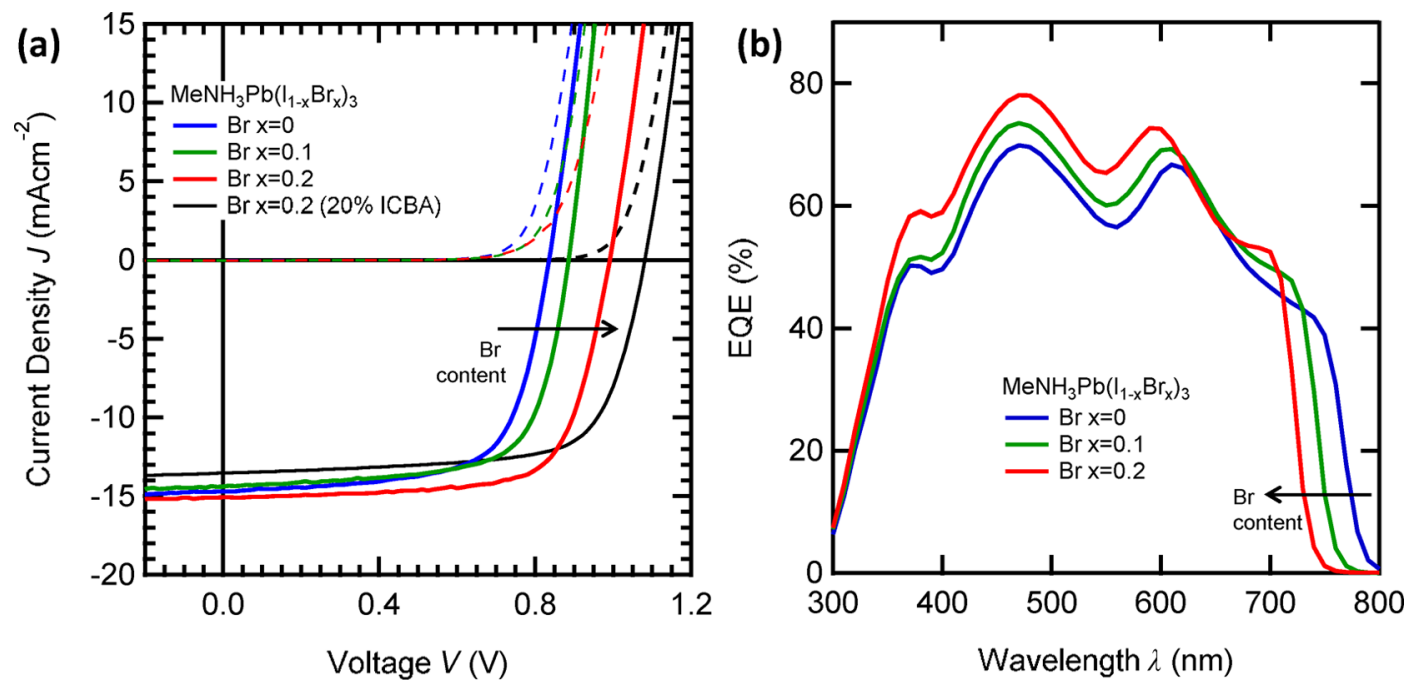

Figure 1. Device performance: (a) AM1.5 J-V response and (b) EQE of ITO/PEDOT:PSS $/ \mathrm{CH}_{3} \mathrm{NH}_{3}\left(\mathrm{I}_{1-x} \mathrm{Br}_{x}\right)_{3} / \mathrm{PCBM} / \mathrm{Ca} / \mathrm{Al}$ as a function of bromine composition. The increase in perovskite band gap with increasing $\mathrm{Br}$ content led to an increase in the device $V_{\mathrm{OC}}$ value. The black $J-V$ curve corresponds to an $x=0.2$ device with 20\% ICBA added to the PCBM, which increased the $V_{\mathrm{OC}}$ value further.

Table 1. Comparison of Energy Shifts Relative to $\mathrm{CH}_{3} \mathrm{NH}_{3} \mathrm{PbI}_{3}$ as a Function of Br Content in $\left.\mathrm{CH}_{3} \mathrm{NH}_{3} \mathrm{~Pb}_{\left(\mathrm{I}_{1-x}\right.} \mathrm{Br}\right)_{3} \mathrm{Planar}$ Cells

$\begin{array}{cccccc}\text { Br content } & \Delta V_{\mathrm{OC}^{a}}{ }^{a}( \pm 0.007)(\mathrm{V}) & \Delta E_{\text {opt }^{b}}( \pm 0.09)(\mathrm{eV}) & \Delta V_{\text {ele }}{ }^{c}( \pm 0.009)(\mathrm{V}) & \Delta V_{\text {kin }}{ }^{d}( \pm 0.005)(\mathrm{V}) & \Delta V_{\text {eff }}\left(\Delta V_{\text {ele }}+\Delta V_{\text {kin }}\right)( \pm 0.010)(\mathrm{V}) \\ 0 \rightarrow 0.10 & +0.026 & +0.07 & +0.081 & -0.053 & +0.028 \\ 0 \rightarrow 0.20 & +0.173 & +0.12 & +0.227 & -0.056 & +0.171\end{array}$

${ }^{a} V_{\mathrm{OC}}$ at 1 sun. ${ }^{b} \Delta E_{\text {opt }}$ from optical absorption measurements (Figure S1). ${ }^{c}$ Effective electronic band-gap shift $\left(\Delta V_{\text {ele }}\right.$ ) from $n$ vs $V_{\mathrm{OC}}$ (Figure $\left.3 \mathrm{a}\right)$ at $3.5 \times 10^{15} \mathrm{~cm}^{-3}$. ${ }^{d}$ Kinetic shift $\left(\Delta V_{\text {kin }}\right)$ from $\tau$ vs $n$ (Figure $3 \mathrm{~b}$ ) at $3.5 \times 10^{15} \mathrm{~cm}^{-3}$.

1-sun equivalent background illumination; this should be within the small-perturbation regime and avoids the $V_{\mathrm{OC}}$ shunt-limited regime at low light intensity.

\section{RESULTS}

3.1. Device Characterization. Figure 1 shows plots of the $J-V$ performance and external quantum efficiency (EQE) spectra of the planar hybrid perovskite solar cells studied in this work. Devices were fabricated with the device structure ITO/ PEDOT:PSS $/ \mathrm{CH}_{3} \mathrm{NH}_{3} \mathrm{~Pb}\left(\mathrm{I}_{1-x} \mathrm{Br}_{x}\right)_{3} / \mathrm{PCBM} / \mathrm{Ca} / \mathrm{Al}$ following literature procedures, as detailed in the Experimental Section. Perovskite and PCBM layer thicknesses were consistently measured to be 300 and $30 \mathrm{~nm}( \pm 5 \mathrm{~nm})$, respectively, for all devices. We focus on the range of $\mathrm{Br}$ contents $x$ from 0 to 0.2; higher levels of bromide substitution resulted in large losses of device performance and reproducibility, due to the disruption of the crystal structure and probable light-induced halide segregation. This light-induced halide segregation, which has been well-documented in films, remains largely unstudied in devices. ${ }^{9,33-36}$ Although not observed in the range of compositions studied, we believe that the methods demonstrated herein would be well-suited for further study of these phenomena. Cells were measured under simulated AM1.5 illumination and exhibited negligible hysteresis over the scan speeds and temperatures employed (see Figure S2 in the Supporting Information). Box plots of the device-to-device performance variability can also be found in the Supporting Information (Figure S3). Devices employed for the transient studies reported herein showed device efficiencies ranging from $8.3 \%( \pm 0.2 \%)$ for the $\mathrm{CH}_{3} \mathrm{NH}_{3} \mathrm{PbI}_{3}$ device to $10.7 \%( \pm 0.2 \%)$ for the $\mathrm{CH}_{3} \mathrm{NH}_{3} \mathrm{~Pb}\left(\mathrm{I}_{0.8} \mathrm{Br}_{0.2}\right)_{3}$ device, slightly lower than the initial device performance following fabrication (as reported in
Figure S3) due to initial degradation or burn-in. This decrease is primarily associated with lower current density, with $V_{\mathrm{OC}}$ remaining largely stable; further degradation over the course of the measurements was not observed. Although the device performance reported is lower than the top efficiencies reported for this architecture, the associated trends, particularly in $V_{\mathrm{OC}}$, as is the focus herein, with the range of $\mathrm{Br}$ contents studied are consistent with the results of Noh et al. and other higher-performing examples. ${ }^{8,9,27}$ All devices showed good linearity of $J_{\mathrm{SC}}$ as a function of light intensity (Figure S4), suggesting that nonlinear recombination processes are not a significant limitation at short circuit because of good charge collection. This study focused instead on the impact of recombination losses on $V_{\mathrm{OC}}$. It is apparent that substitution of $20 \%$ bromide into the material resulted in an increase in $V_{\mathrm{OC}}$ from $0.836( \pm 0.005) \mathrm{V}$ to $1.009( \pm 0.005) \mathrm{V}$ (Figure 1a), correlated with an increase in the optical band gap from 1.56 $( \pm 0.09) \mathrm{eV}(795 \mathrm{~nm})$ to $1.68( \pm 0.09) \mathrm{eV}(738 \mathrm{~nm})$ (determined from the optical absorbance onset), as is apparent from the EQE spectrum (Figure 1b) and the optical absorbance spectrum (Figure S1). It is of particular note that the change in $V_{\mathrm{OC}}(173 \mathrm{mV})$ was almost $50 \%$ larger than the change in optical band gap $(120 \mathrm{meV})$, as detailed in Table 1 , clearly indicating that measurements of the optical band gap alone are not a quantitative indicator of changes in cell voltage. A further $73( \pm 7) \mathrm{mV}$ increase in voltage was observed for $20 \%$ bromide with the substitution of $20 \%$ ICBA into the PCBM electron layer, as discussed further below. In this study, we combined differential charging as a measure of electronic, rather than optical, band gap with transient photovoltage measurements of carrier lifetime to obtain a quantitative understanding of device $V_{\text {OC. }}$ 

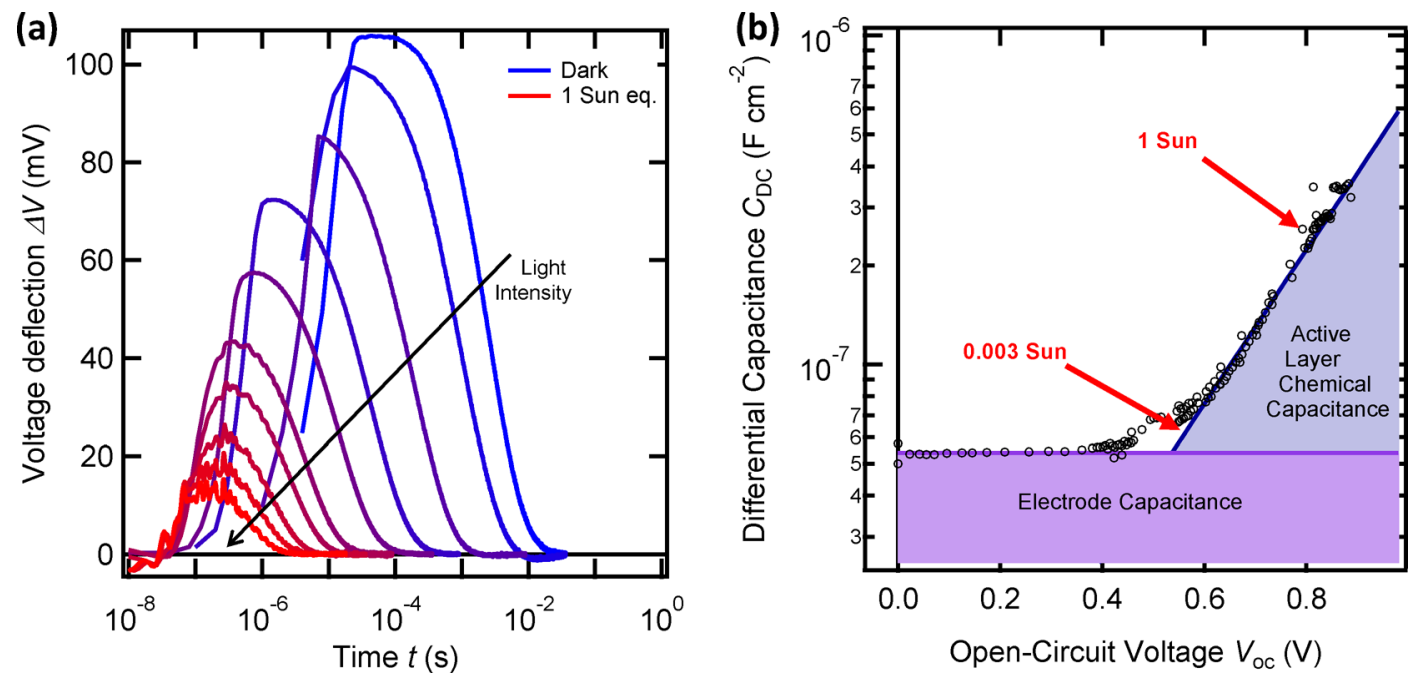

Figure 2. Transient voltage and capacitance response: (a) Decay of the transient photovoltage over a range of light intensities between darkness and 1 sun for a pure MAPI planar hybrid perovskite. (b) Differential capacitance measured from transient photocurrent and transient photovoltage as a function of the open-circuit voltage $\left(V_{\mathrm{OC}}\right)$ over a range of background light intensities from 0 to 5 sun equivalents.

3.2. Optoelectronic Measurements. The kinetic approach applied herein to analyze $V_{\mathrm{OC}}$ is based on the balance between carrier generation, $J_{\text {gen }}(V)$, and recombination currents, $J_{\text {loss }}(V)$. At $V_{\mathrm{OC}}$ under steady-state conditions, no external current flows; therefore, the generation and recombination currents must be equal: $J_{\text {gen }}\left(V_{\mathrm{OC}}\right)=J_{\text {loss }}\left(V_{\mathrm{OC}}\right)$. The size of $V_{\mathrm{OC}}$ can therefore be understood if both the generation current and the recombination current can be measured. We assumed carrier generation efficiency to be voltage-independent between short circuit and open circuit for high-permittivity perovskite materials. If recombination losses at short circuit are low because of sufficiently fast carrier extraction, as supported for the cells herein by observation of a linear dependence of $J_{\mathrm{SC}}$ on light intensity (Figure S4), we can use $J_{\text {gen }}(V)=J_{\text {gen }}=J_{S C}$ for each light intensity employed.

Small-perturbation transient photovoltage (TPV) decays were employed as an assay of charge-carrier recombination; typical transients are shown in Figure 2a for $\mathrm{CH}_{3} \mathrm{NH}_{3} \mathrm{PbI}_{3}$ device as a function of background light intensity. In all cases, the decays could be reasonably fitted by single-exponential decays (Figure S10), consistent with the small-perturbation limit employed in these studies. We note that this situation contrasts with previous TPV analyses of perovskite devices employing mesoporous titania electron-collection layers, which exhibited more complex biexponential decays, associated with the hysteresis phenomena observed in these devices. ${ }^{18,22}$ It is also apparent that the time scale of the TPV decays observed for the $\mathrm{CH}_{3} \mathrm{NH}_{3} \mathrm{PbI}_{3}$ device studied herein varies by several orders of magnitude with light intensity, with exponential decay times ranging from $1.60 \mathrm{~ms}$ at $9 \times 10^{-5}$ sun equivalent (corresponding to $V_{\mathrm{OC}}=0.429 \mathrm{~V}$ ) to $0.59 \mu \mathrm{s}$ at 1 sun (corresponding to $V_{\mathrm{OC}}=0.813 \mathrm{~V}$ ). This strong dependence is indicative of charge recombination in these devices accelerating strongly as the charge density in the device is increased under stronger irradiation. Such a dependence is at least qualitatively consistent with transient optical studies of excitation-intensitydependent bimolecular recombination in $\mathrm{CH}_{3} \mathrm{NH}_{3} \mathrm{PbI}_{3}$ films. ${ }^{37}$

We now turn to an analysis of the charge density in the device at open-circuit voltage over a range of light intensities relevant for typical device operation. To perform this analysis, we use the method of differential charging (DC), a combination of transient photocurrent (TPC) and transient photovoltage (TPV) measurements. ${ }^{15,18}$ The differential capacitance $C_{\mathrm{DC}}$ is calculated at each $V_{\mathrm{OC}}$ value as

$$
C_{\mathrm{DC}}=\frac{\Delta Q}{\Delta V_{0}\left(V_{\mathrm{OC}}\right)}
$$

where $\Delta Q$ is the short-circuit photogenerated charge from the small-perturbation laser pulse, measured from the TPC, and $\Delta V_{0}$ is the corresponding initial open-circuit voltage deflection during TPV. We note that charge extraction, a widely used alternative method for determining charge density, gave unreasonably large charge densities, as has been noted previously, ${ }^{18}$ and so was not used in this study (see the Supporting Information for a discussion of this point). Crucially, DC provides a small-perturbation measurement that does not involve a large switch in internal field during the measurements; rather, measurements at short circuit and open circuit are undertaken independently under steady-state conditions after any significant hysteresis or polarization.

The differential capacitance for a representative $\mathrm{CH}_{3} \mathrm{NH}_{3} \mathrm{PbI}_{3}$ planar device can be seen in Figure $2 \mathrm{~b}$. It is apparent that this capacitance exhibits two regimes depending on the size of the quasi-Fermi-level splitting of $V_{\mathrm{OC}}$ (controlled by the background light intensity). At low light levels, the differential capacitance is independent of voltage and has a value of $55.5 \mathrm{nF} \mathrm{cm}$. This capacitance is in reasonable agreement with the geometric capacitance of the device electrodes, which is expected to dominate at low quasi-Fermilevel splitting, corresponding to an effective relative dielectric constant for MAPI of 19, consistent with values reported by others for this type of device. ${ }^{38,39}$ This capacitance is therefore assigned to charging of the device electrodes, with electrode charge constituting a significant fraction of charge accumulation at low light levels. At an equivalent light intensity of $0.3 \%$ of 1 sun, there is a transition to the differential capacitance varying approximately exponentially with voltage, with a slope in the range of $(0.2-0.33) k T$. This can be primarily assigned to the chemical capacitance of the active layer, corresponding to the charge stored in the perovskite photoactive layer as the quasiFermi levels approach the semiconductor conduction- and 

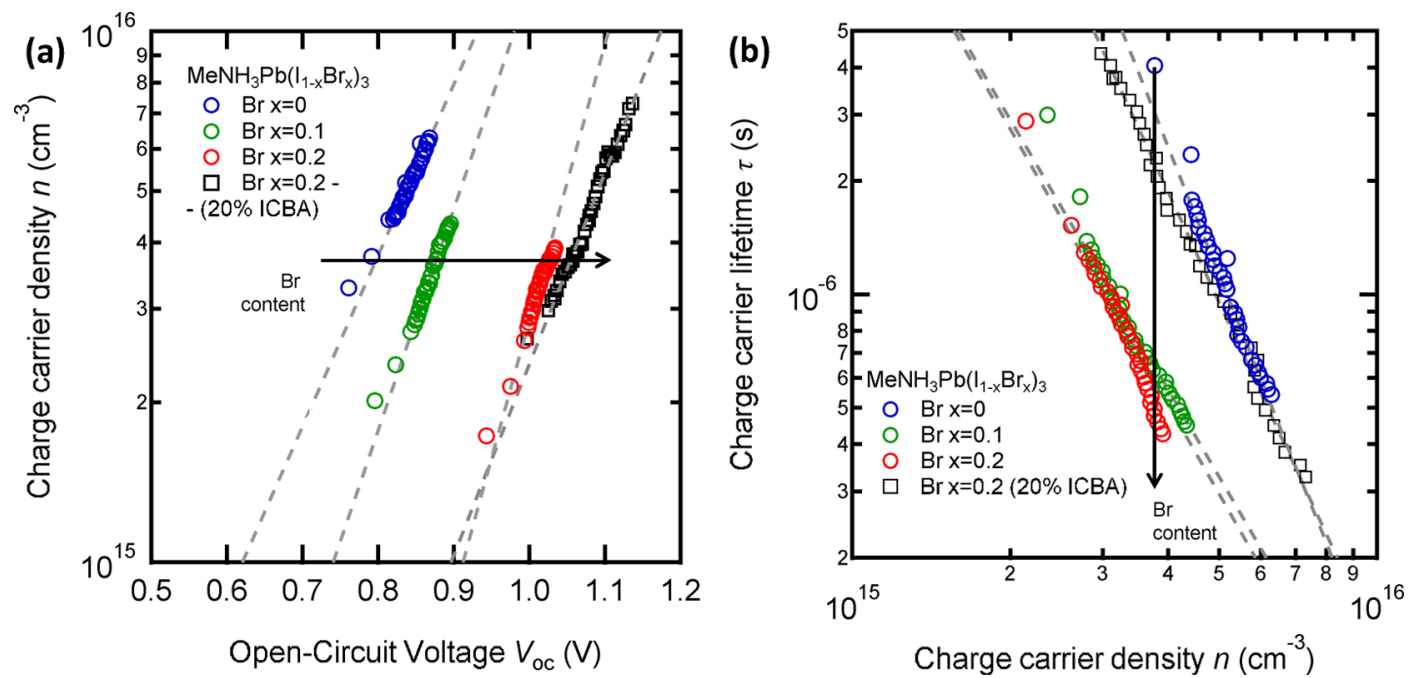

Figure 3. Optoelectronic characterization: (a) Active-layer charge-carrier density $\left(n_{\mathrm{AL}}\right)$ as a function of quasi-Fermi-level splitting $\left(V_{\mathrm{OC}}\right)$. (b) Average charge-carrier lifetime $(\tau)$ as a function of $n_{\mathrm{AL}}$ for $\mathrm{CH}_{3} \mathrm{NH}_{3} \mathrm{~Pb}\left(\mathrm{I}_{1-x} \mathrm{Br}_{x}\right)_{3}$ cells with $\mathrm{Br}$ contents of $x=0,0.1$, and 0.2 . The same approximate range of light intensities, between 0.1 and 3 sun equivalents, was used for each material system. The results for the use of $20 \%$ ICBA in PCBM for the $x=0.2$ device is shown with black squares. Gray dashed lines represent fits according to (a) eq 2 and (b) eq 3.

valence-band edges, supported by our studies as a function of bromide substitution, as discussed below.

The total excess charge $Q$ stored in the device at open circuit $\left(V_{\mathrm{OC}}\right)$ can be calculated by integration of the differential capacitance with $V_{\mathrm{OC}} \cdot{ }^{15}$ Using this integration, we found the total excess charge present in the device under 1-sun conditions at open circuit to be $70 \mathrm{nC} \mathrm{cm}$ (shown in Figure S8), with approximately $45 \%$ stored in the perovskite layer (corresponding to a charge density of $6.6 \times 10^{15} \mathrm{~cm}^{-3}$ ) and the remainder on the device electrodes.

We note that the decay dynamics of TPC transients used to determine $C_{\mathrm{DC}}$ exhibited decay times similar to, and in some cases slower than, the TPV transients at similar light intensities (Figure S9), unusual for a material system known for high fill factors (FFs) and efficient collection at short circuit. These slower TPC decay dynamics appear to be RC-limited, associated in particular with slow transport dynamics in the PCBM electron-collection layer. The RC time constant for the MAPI device studied above is $0.8 \mu \mathrm{s}$, determined from the electrode capacitance of $55.5 \mathrm{nF} \mathrm{cm}^{-2}$ measured above and the measured device series resistance of $150 \Omega$, in good agreement with our measured TPC decay kinetics (see Figure S9). (This RC limitation does not impede the validity of our differential capacitance analysis, as discussed in the Supporting Information.) The origin of this relatively slow RC time constant was investigated by varying the PCBM layer thickness (see Figure S6) and using the TPV rise time as a transport measurement that avoids the RC limitations. ${ }^{40}$ At low irradiance conditions, where the electrode capacitance dominates over the active-layer capacitance and, therefore, the generation of cell voltage requires electron transport through the PCBM to the metal top electrode, the photovoltage rise time was observed to increase from being instrument-response-limited (190 ns) for a 40-nm PCBM layer to $250 \mathrm{~ns}$ for a 150 -nm-thick layer, correlated with an increase in series resistance $\left(R_{\mathrm{s}}\right)$ from 55 to $150 \Omega$. Using the voltage drop across the low-dielectric PCBM $\left(V_{\mathrm{PCBM}}=\right.$ $V_{\mathrm{bi}} C_{\mathrm{tot}} / C_{\mathrm{PCBM}}$, where $V_{\mathrm{bi}}$ is the built-in voltage, $C_{\mathrm{tot}}$ is the total capacitance, and $C_{\mathrm{PCBM}}$ is the capacitance of the PCBM layer), a drift carrier mobility of $9.7 \times 10^{-4} \mathrm{~cm}^{2} \mathrm{~V}^{-1} \mathrm{~s}^{-1}$ can be estimated (see Supporting Information), consistent with literature data, ${ }^{41,42}$ and significantly lower than the high reported mobilities in MAPI $\left(1 \mathrm{~cm}^{2} \mathrm{~V}^{-1} \mathrm{~s}^{-1}\right) .{ }^{11}$ As well, the $J-V$ curve for the thick PCBM layers (Figure S7) shows a reduced fill factor and the presence of an S-shape, consistent with a buildup of space charge due to the restriction of carriers out of the device. ${ }^{43}$ Both results are indicative of the charge extraction from the device (and therefore the cell resistance) being limited by the PCBM layer.

3.3. Energetics and Recombination Kinetics. We now turn to a consideration of the impact of bromide substitution on the charge accumulation and recombination dynamics and, thereby, on the cell voltage in the planar perovskite cells studied herein. We focus on the high-light-level regime $(10-300 \%$ of 1 sun) most relevant to practical device operation, where, for all devices, the active-layer chemical capacitance was determined to dominate over the electrode capacitance. Figure 3a shows the total average excess charge density in the active layer, $n_{\mathrm{AL}}$, at open circuit as calculated from differential charging for cells with varying bromine contents. In comparison to the values for typical organic photovoltaic (OPV) devices, ${ }^{32,44} n_{\mathrm{AL}}$ was observed to be lower for the perovskite devices studied herein, consistent with the faster bimolecular recombination kinetics limiting charge accumulation in the active layer of the perovskite devices at open circuit. At low light levels, all devices exhibited similar dependencies of the total accumulated charge $Q$ on $V_{\mathrm{OC}}$, consistent with this charge being associated with the electrode capacitance, independent of the active-layer energetics (see Figure S12). At higher light levels, for all devices, the charge started to increase exponentially with $V_{\mathrm{OC}}$, assigned as above to increasing charge accumulation in the active layer of the device. Bromide substitution was observed to result in an increase in the voltage at which this active-layer charge accumulation started to dominate over electrode charge. This is consistent with the increase in perovskite band gap with bromide substitution, as indicated by the optical measurements above, and confirms our assignment of this exponentially increasing charge to active-layer charge.

More quantitatively, $n_{\mathrm{AL}}$ was well fitted to the exponential function 

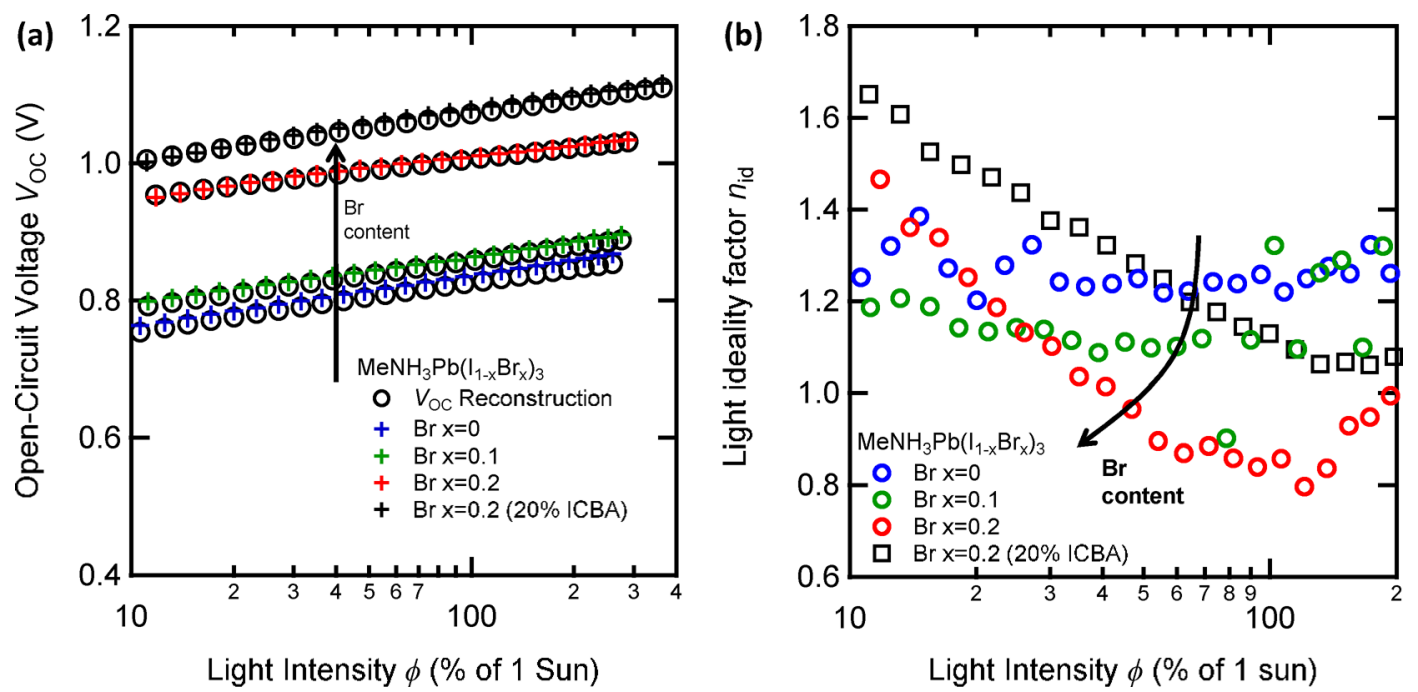

Figure 4. Light-intensity-dependent $V_{\mathrm{OC}}$ and ideality factor: (a) Measured (crosses) and reconstructed (circles) open-circuit voltage values as a function of illumination intensity for $\mathrm{CH}_{3} \mathrm{NH}_{3} \mathrm{~Pb}\left(\mathrm{I}_{1-x} \mathrm{Br}_{x}\right)_{3}$ cells with $\mathrm{Br}$ contents of $x=0,0.1$, and 0.2 . (b) Light ideality factor as a function of light intensity, calculated from the slope of $V_{\mathrm{OC}}$ versus light intensity. The effect of adding 20\% ICBA to the PCBM is shown in black.

$$
n_{\mathrm{AL}}=n_{0} \exp \left(\frac{q V_{\mathrm{OC}}}{m k_{\mathrm{B}} T}\right)
$$

where $n_{0}$ and $m$ are experimentally derived constants. $m$ specifies how the slope of $n\left(V_{\mathrm{OC}}\right)$ deviates from the thermal voltage $k T / q$. Values of $m$ for the cells studied here were in the range of $3-5$, decreasing slightly with increasing bromide content. Although in certain situations $m$ can be used as a measure of the shape of the density of states, it can be influenced by factors such as doping or surface recombination as a result of spatially inhomogeneous charge distributions. ${ }^{45}$ If we assume the simple relation $n \propto \exp \left(q V / 2 E_{\mathrm{ch}}\right)$, where $E_{\mathrm{ch}}$ is the characteristic energy (see ref 45 for more details), to be valid for intrinsic semiconductors, slopes in the range $3<m<5$ suggest a characteristic energy for the density of states of 37.5$62.5 \mathrm{meV}$. The shift of $n_{\mathrm{AL}}$ with bromide substitution allows for the quantification of the increase in the effective electronic band gap with increasing bromide concentration. We note that the term "effective electronic band gap" refers to the onset of charge accumulation as a function of quasi-Fermi-level splitting; this might differ from the threshold for photon absorption characterized by the optical band gap due to the presence of optically dark states and polaronic or excitonic effects. Taking $3.5 \times 10^{15} \mathrm{~cm}^{-3}$ as a representative charge density, we conclude that $10 \%$ bromide substitution results in an $81 \pm 9 \mathrm{meV}$ increase in this effective electronic band gap and $20 \%$ substitution results in a $227 \pm 9 \mathrm{meV}$ increase. We note that these increases in effective electronic band gap with bromine substitution are larger than the increases in optical band gap discussed above (see Table 1 for a comparison).

Before considering the impact of this increased effective electronic band gap on $V_{\mathrm{OC}}$, we address the impact of bromide substitution on the charge-carrier lifetimes. TPV transients analogous to those shown in Figure 2a were collected as a function of bromide substitution. These TPV transients were fitted using a monoexponential from which the smallperturbation carrier lifetime $\tau_{\Delta n}$ was determined. $\tau_{\Delta n}$ can be related to the pseudo-first-order carrier lifetime $\tau_{n}=\delta \tau_{\Delta n}$, an average of all potential recombination mechanisms across the entire device, where $\delta$ is the overall recombination order with respect to $n$ as defined by $J_{\text {loss }}=k n^{\delta}$, where $k$ is a rate coefficient independent of $n$. The dependence of carrier lifetime on carrier density is plotted in Figure $3 \mathrm{~b}$. It is apparent that the carrier lifetime exhibits a power-law dependence on charge density, as expected for a bimolecular charge recombination process of the form

$$
\tau_{n}=\tau_{n_{0}}\left(\frac{n}{n_{0}}\right)^{(1-\delta)}
$$

where $n_{0}$ was defined above and $\tau_{n_{0}}$ is an experimentally derived constant from the voltage dependence of $\tau_{n}$. Further discussion and derivations can be found in the Supporting Information and elsewhere. ${ }^{17,32,44,46}$ This pseudo-first-order carrier lifetime for all three compositions is seen to have an approximate $n^{-2}(\delta$ $\approx 3$ ) dependence on active-layer charge-carrier density, over the range of $n$ values studied. Further interpretation of this order would be unwise without further knowledge of doping densities and the spatial distribution of charges; however, in an undoped and sufficiently thick device, it would be compatible with recombination through trap states. ${ }^{46}$ We note that this bimolecular recombination will include both radiative and nonradiative recombination processes.

When comparing the recombination dynamics of material systems with different energetic profiles, it is important to address how lifetime varies with carrier density, rather than cell voltage. It is apparent from Figure $3 \mathrm{~b}$ that, for matched carrier densities, the recombination lifetime was shortened by addition of $\mathrm{Br}$ to the perovskite structure. This acceleration of charge recombination losses with bromine substitution was also apparent from approximately 2 -fold lower accumulated charge densities observed for the bromine-substituted devices for matched light intensities (see Figure 3a). Again, taking $3.5 \times$ $10^{15} \mathrm{~cm}^{-3}$ as a representative charge density, one can see from Figure $3 \mathrm{~b}$ a shortening of the lifetime from $4.08( \pm 0.23) \mu \mathrm{s}$ in $\mathrm{CH}_{3} \mathrm{NH}_{3} \mathrm{PbI}_{3}$ to $0.80( \pm 0.08) \mu$ s at $10 \%$ bromide content and $0.73( \pm 0.04) \mu$ s at $20 \%$ bromide content, indicating a 5 -fold reduction in carrier lifetime following bromine substitution, calculated to result in a $56( \pm 5) \mathrm{mV}$ loss of cell voltage (see the Supporting Information for calculation details). This shortening 


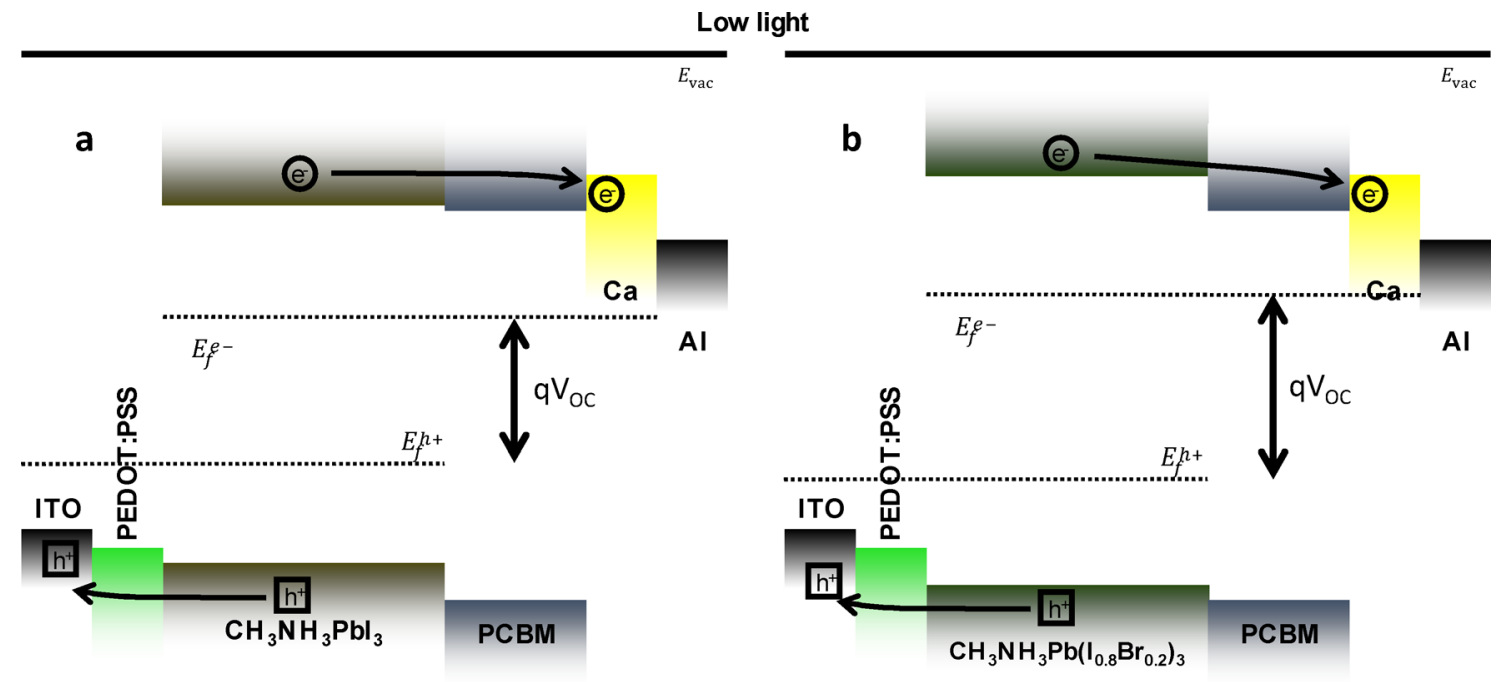

High light
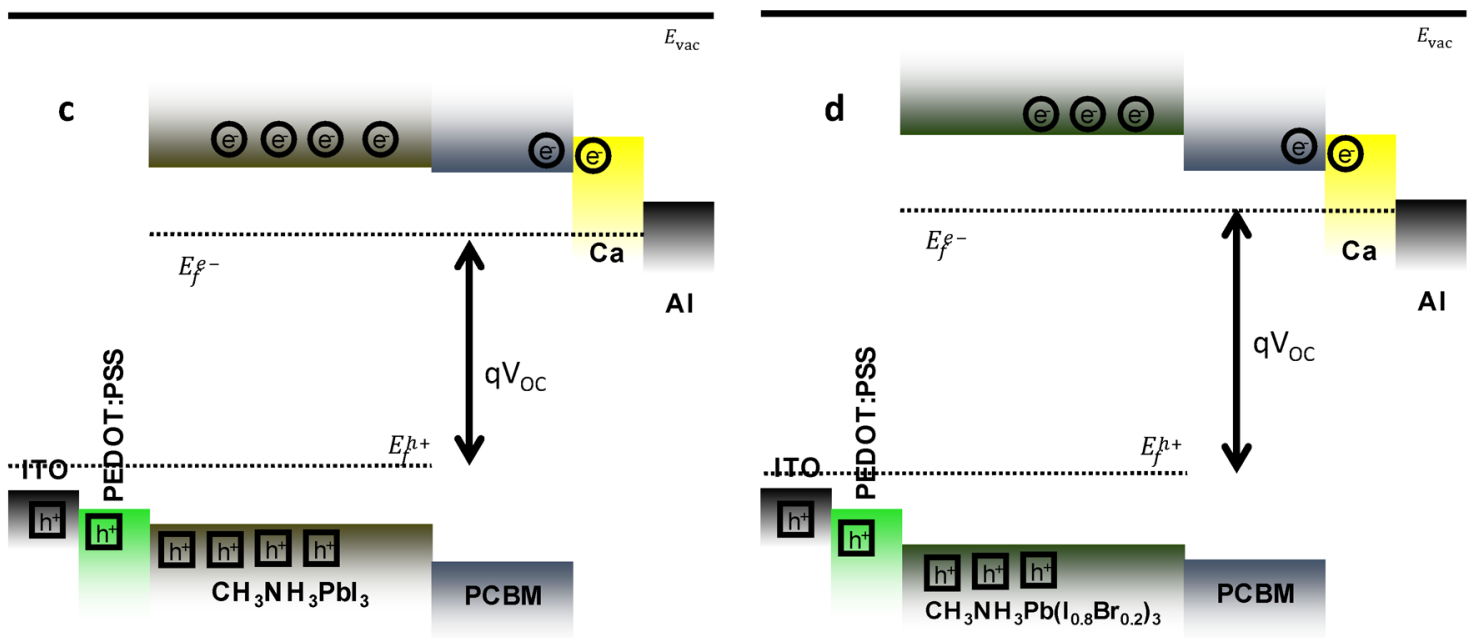

Figure 5. Energy diagrams: (a,c) $\mathrm{CH}_{3} \mathrm{NH}_{3} \mathrm{PbI}_{3}$ and $(\mathrm{b}, \mathrm{d}), \mathrm{CH}_{3} \mathrm{NH}_{3} \mathrm{~Pb}\left(\mathrm{I}_{0.8} \mathrm{Br}_{0.2}\right)_{3}$. (a,b) Low light intensity, where charges are mostly on the electrodes. (c,d) Light intensity closer to 1 sun, where charges begin to build up in the active layer. Even though panel d shows a greater voltage than panel $\mathrm{c}$ because of the increase in band gap, faster recombination leads to less charge in the active layer and quasi-Fermi levels that are not able to approach the band edges as much.

of carrier lifetime tends to decrease the photovoltage for a given $J_{\text {gen }}$ value, somewhat opposing the shift in the density of states to higher energies with increasing $\mathrm{Br}$ content, as seen in Figure $3 a$.

3.4. $V_{O C}$ Reconstruction and Device Ideality. If this description of in situ energetics and recombination kinetics is accurate, it should be possible to reconstruct the $V_{\mathrm{OC}}$ of the measured devices over the range of light intensities studied. As discussed above, at open circuit, the recombination loss current $J_{\text {loss }}=(q n d) / t_{n}$, where $d$ is the thickness of the active layer, must be equal to the generation current $J_{\text {gen, }}$ assumed to equal $J_{\mathrm{SC}}$. From eqs 2 and 3, it is possible to obtain a simple expression for $V_{\mathrm{OC}}$ as

$$
V_{\mathrm{OC}}^{\text {calc }}=\frac{m k_{\mathrm{B}} T}{q \delta} \ln \left(\frac{J_{\mathrm{SC}} \tau_{n_{0}}}{q n_{0} d}\right)
$$

where all of the terms were obtained directly from our measured TPV decays and DC data and $J_{\mathrm{SC}}$ was measured under the same irradiation conditions at short circuit. Figure 4a shows the resulting calculated device open-circuit voltages $V_{\mathrm{OC}}^{\text {calc }}$ determined using eq 4 overlaid on the directly measured voltages $V_{\mathrm{OC}}$. It is apparent that there is excellent agreement $( \pm 5 \mathrm{mV})$ between our calculated and measured values for $V_{\mathrm{OC}}$. Thus, our simple device model and transient optoelectronic analyses are able to yield not only the correct absolute opencircuit voltage for these devices but also the variation of the voltage with light intensity and bromine substitution. The excellent correlation between the calculated and measured $V_{\mathrm{OC}}$ values over such a range of light intensities, reflecting real-life operating conditions, demonstrates the applicability of the discussed optoelectronic techniques in the study of perovskite photovoltaics. This agreement, along with the data in Table 1, furthermore demonstrates how energetic changes and kinetic changes combine to give the observed device voltage.

Finally, Figure $4 \mathrm{~b}$ shows the light ideality factor, as calculated from the derivative of the voltage as a function of light intensity, $n_{\mathrm{id}}=\left(q \mathrm{~d} V_{\mathrm{OC}}\right) /\{k T[\mathrm{~d} \ln (\phi)]\} .{ }^{47}$ A value of 1 is nominally assigned to the recombination of free charges or to recombination at the semiconductor electrode interfaces, whereas a value of 2 is assigned to the recombination of free 
charge with a trap state toward midgap. ${ }^{48}$ The observed values for $n_{\text {id }}$ for the devices studied herein are in the range of 1-1.5, that is, lower than the values of $n_{\mathrm{id}} \approx 2$ commonly reported in the literature. ${ }^{3,49,50}$ The open-circuit voltages obtained in our devices are substantially lower than the radiative open-circuit voltage of MAPI, which is about $1.33 \mathrm{~V},{ }^{51,52}$ indicating that radiative free-carrier recombination, one possible source of $n_{\mathrm{id}}=$ 1 , is not dominant in our devices. Figure $4 \mathrm{~b}$ shows the $n_{\mathrm{id}}$ decreased as the $\mathrm{Br}$ content was increased. In the case of $20 \%$ $\mathrm{Br}$, a clear reduction in $n_{\mathrm{id}}$ with increasing light intensity can be seen. This is a common observation for devices in which surface recombination becomes a dominant loss pathway, resulting in increased Fermi-level pinning as $V_{\mathrm{OC}}$ approaches the built-in voltage $V_{\mathrm{bi}} \cdot{ }^{43,47}$

To further investigate the potential for surface recombination at the perovskite/fullerene interface to limit $V_{\mathrm{OC}}$ of the bromine-substituted devices, devices with $20 \% \mathrm{Br}$ content were fabricated with the PCBM layer containing 20\% ICBA. ICBA has a higher-lying lowest unoccupied molecular orbital (LUMO) energy than PCBM and, therefore, has the potential to reduce the energy offset between the perovskite and fullerene layers. An ICBA content of $20 \%$ was the bestperforming ICBA:PCBM ratio and was chosen to emphasize the improvement in $V_{\mathrm{OC}}$, and reduction in $V_{\mathrm{OC}}$ pinning, that can be achieved through a simple modification of the interlayer. The $J-V$ performance in Figure 1a shows a further increase in device $V_{\mathrm{OC}}$ of $73( \pm 7) \mathrm{mV}$ to $1.082( \pm 0.005) \mathrm{V}$. The corresponding energetic and kinetic data are shown in Figure 3. The change in voltage with inclusion of ICBA primarily resulted in a suppression of the faster carrier lifetimes (Figure $3 \mathrm{~b}$ ), observed for the Br-containing perovskites, returning the measured lifetimes to values comparable to those of the pure MAPI/PCBM system. A small decrease in the charge density at a given $V_{\mathrm{OC}}$ was also observed (Figure $3 \mathrm{a}$ ), consistent with a higher fullerene LUMO level, alongside an increase in device ideality factor, consistent with a reduction in surface recombination losses (Figure $4 \mathrm{~b}$ ). Although a full analysis of the effects of ICBA substitution on device performance is beyond the scope of this work, these results are also indicative of the $V_{\mathrm{OC}}$ of bromine-substituted devices being increasingly limited by higher surface recombination losses due to the larger perovskite/fullerene LUMO level offset, with this effect being most prominent at high light intensities.

\section{DISCUSSION}

We have reported above a combined differential charging and photovoltage transient optoelectronic analysis of the opencircuit voltage of planar organic/inorganic hybrid perovskite solar cells as a function of light intensity and bromine substitution. Using these data, a simple device model can correctly reconstruct (to with $\pm 5 \mathrm{mV}$ ) both the absolute device open-circuit voltage and its dependence on light intensity and bromine substitution without any fitting parameters. This excellent agreement provides strong evidence for the validity of both this simple model and this experimental approach for the analysis of photovoltage generation in such devices. We first discuss the general implications of this agreement, before going on to discuss in detail the implications for the effect of bromine substitution.

At low light levels, the measured charge density in the device was found to be in good agreement with that estimated by treating the device as a simple parallel-plate capacitor with charge accumulating primarily on the device electrodes. At higher light levels, the cell capacitance starts to increase exponentially with applied potential, indicative of the increasing dominance of an "electronic chemical capacitance", corresponding to increasing charge accumulation in the active layer(s) (or, more specifically, the intrinsic or not strongly doped materials) of the device, as illustrated in Figure 5a,c. This chemical capacitance shifts with bromine substitution, consistent with at least one photogenerated charge carrier accumulating in the perovskite layer of the device at open-circuit and 1-sun conditions. We note that, from the data herein, it is not possible to rule out that one of the charge carriers contributing to this chemical capacitance is accumulating in an interlayer (i.e., holes on the PEDOT:PSS layer or electrons on the PCBM). This contrasts with photoluminescence quenching data, typically obtained at low light irradiances, which shows strong photoluminescence quenching upon the addition of either PEDOT:PSS or PCBM hole- and electron-collection layers. $^{13}$

The chemical capacitance of the devices studied here was observed to increase exponentially with open-circuit voltage, with an exponent of $q / m k T$, where $m=3-5$. This deviates from the ideal behavior $(m=2)$ of an intrinsic semiconductor, indicative of a significant tail of intraband gap or shallow trap states, likely resulting from the presence of other (organic) semiconducting layers. We note that this characteristic energy for the tail of electronic states is larger than the observed Urbach tail from optical measurements of perovskite films. ${ }^{53,54}$ This distinction between optical and electronic measurements of densities of states can also be observed in the difference we observed between the increases in optical and effective electronic band gaps with bromine substitution (see Table 1), although a full understanding of this point, and the potential impact of energetic alignment shifts at the device interfaces, is beyond the scope of this study.

The charge-carrier lifetimes measured for the devices studied herein were observed to be strongly dependent on light intensity and charge-carrier density, as seen from an overall order of recombination of $\delta>3$. Lifetimes were in the range of $\sim 50 \mathrm{~ns}$ under 3-sun irradiation to $80 \mu \mathrm{s}$ under 0.01-sun irradiation (Figure 2a). The large retardation in lifetime with decreased light irradiation can be attributed, in part, to a proportionally increased charge localization on the device electrodes compared to the active layer, resulting in a more effective spatial separation of the photogenerated charges. At higher light levels, the lifetime is likely to be dominated by the recombination of charge carriers in the perovskite layer. Although a full analysis of this light- and charge-densitydependent behavior is beyond the scope of this work, the highlight-level data, where the active-layer charge dominates, indicates a charge-density-dependent bimolecular recombination rate coefficient (Figure S13) in the range from $1 \times 10^{-10}$ to $3 \times 10^{-10} \mathrm{~cm}^{3} \mathrm{~s}^{-1}$ at light intensities in the range from 0.5 to 3 suns, reasonably consistent with previous observations from transient optical and terahertz transient photoconductivity measurements of MAPI layers alone. ${ }^{12,37}$

Twenty percent bromine substitution was observed to result in a $173( \pm 7) \mathrm{mV}$ increase in device $V_{\mathrm{OC}}$ relative to that of the pure MAPI device. This increase in cell voltage was found to result primarily from a $227( \pm 9) \mathrm{mV}$ increase in active-layer effective electronic band gap as determined from the shift in carrier density. This increase in perovskite electronic band gap was partly offset by a 5-fold acceleration of recombination kinetics (measured at matched charge densities), calculated to 
result in a $56( \pm 5) \mathrm{mV}$ loss of cell voltage, resulting in a calculated net voltage increase of $171( \pm 10) \mathrm{mV}$, in excellent agreement with experimental observations. In other words, the acceleration of recombination losses with bromine substitution prevented the device quasi-Fermi levels from approaching the band edges as closely as would be obtained for the pure MAPI device, as illustrated in Figure 5c,d. The shift in chemical capacitance with bromine substitution confirms the assignment of this chemical capacitance to one or both charge carriers accumulating in the perovskite layer.

Regarding the origin of the acceleration of recombination losses with bromine substitution, it appears consistent with that reported previously for the formamidinium lead mixed-halide system $\mathrm{FAPb}\left(\mathrm{Br}_{x} \mathrm{I}_{1-x}\right)_{3} .{ }^{36}$ This was attributed to an increase in disorder as a result of the disruption of material crystallinity ${ }^{9}$ or a change in direct recombination as a result of varying band edges. It might also result from changes in morphology possible for the different $\mathrm{Br}$ compositions, although scanning electron microscopy (SEM) images showed little change over the $\mathrm{Br}$ range studied (Figure S14). If the perovskite/PCBM interface is important, interpenetration of the PCBM into the perovskite through grain boundaries might also influence the recombination. ${ }^{53}$ A likely additional loss mechanism for full devices is surface recombination, which is expected to increase as the energetic offset between perovskite bands and both the PCBM and PEDOT:PSS interlayers increases. ${ }^{30}$ The increase in $\mathrm{CH}_{3} \mathrm{NH}_{3} \mathrm{~Pb}\left(\mathrm{I}_{1-x} \mathrm{Br}_{x}\right)_{3}$ effective electronic band gap with bromine substitution is accompanied by a decrease in the ideality factor $n_{\mathrm{id}}$, which could correlate with decreasing $m$ value in Figure 3 a as $\delta$ remains constant. ${ }^{43,45,47}$ Studies of organic solar cells have reported analogous changes in ideality in the presence of a dominant surface recombination process. ${ }^{43,56}$ The inclusion of $20 \%$ ICBA in the PCBM layer appears to reduce the impact of recombination at the perovskite/PCBM interface, showing an increase in $n_{\mathrm{id}}$ (and $\mathrm{m}$ ), with the ability to harness the potential voltage gain from the increase perovskite band gap. Because of a higher-lying LUMO in ICBA, the energetic position of the electron quasi-Fermi level generated in the perovskite can be accommodated at a lower fullerene electron population, resulting in reduced recombination at this interface. These observations strongly suggest that optimization of interlayers and electrodes might be required to achieve the highest efficiencies possible from this particular architecture, especially with mixed-halide perovskites.

\section{CONCLUSIONS}

In conclusion, the substitution of iodide with bromide in $\mathrm{CH}_{3} \mathrm{NH}_{3} \mathrm{~Pb}\left(\mathrm{I}_{1-x} \mathrm{Br}_{x}\right)_{3}$ top-cathode planar hybrid perovskite photovoltaics is shown to be an ideal system for demonstrating the applicability of transient optoelectronic techniques for probing the factors influencing the open-circuit voltage of these devices. Differential charging measurements provide insight into the internal energetics and relative charge accumulation, whereas transient photovoltage measurements provide information on the kinetics of charge recombination. An increase in $V_{\mathrm{OC}}$ for higher $\mathrm{Br}$ loadings is attributed to an increase in energetics associated with the increase in perovskite band gap; however, this is somewhat restricted by faster recombination, likely due to increased surface recombination as a result of poorer electrode/interlayer alignment with the perovskite active layer. Remarkably, the measured lifetimes for these devices are not dissimilar from those measured for common organic bulk heterojunction devices. Although lifetimes in
OPVs benefit from charges residing on different molecules, despite the energetic price in LUMO offset, perovskites appear to have the ability to efficiently separate charge, giving long carrier lifetimes compared to what might be expected from the high mobility. Finally, the excellent correlation between calculated and measured $V_{\mathrm{OC}}$ values demonstrates the applicability of these optoelectronic techniques to the description of device performance over a range of light intensities relevant for standard operation. It is hoped the transient optoelectronic methodology presented herein can be used to further understand the origin of changes in recombination in perovskite devices and light-induced band gap pinning in future studies.

\section{ASSOCIATED CONTENT}

\section{Supporting Information}

The Supporting Information is available free of charge on the ACS Publications website at DOI: 10.1021/acs.jpcc.7b02411.

Optical absorbance spectra of $\mathrm{CH}_{3} \mathrm{NH}_{3} \mathrm{~Pb}\left(\mathrm{I}_{1-x} \mathrm{Br}_{x}\right)_{3}$, hysteresis effect on $J-V$ curves, $J-V$ parameter box plots, linearity of $J_{S C}$ with light intensity, charge extraction/differential charging comparison, TPV rise times, PCBM mobility calculations, $J-V$ curves as a function of PCBM thickness, plot of $Q$ vs $V_{\mathrm{OC}}$, examples of TPV and TPC transients, single-exponential TPV fitting example, small-perturbation lifetime $\tau_{\Delta n}$ as a function of $V_{\mathrm{OC}}$, differential capacitance and $Q$ as functions of $\mathrm{Br}$ content, bimolecular recombination rate constant as a function of active-layer charge-carrier density, SEM images of $\mathrm{CH}_{3} \mathrm{NH}_{3} \mathrm{~Pb}\left(\mathrm{I}_{1-x} \mathrm{Br}_{x}\right)_{3}$ perovskite films, calculation of total carrier lifetime, calculation of kinetic voltage change, derivation of eq 4 , and DC/TPV model fitting parameters (PDF)

Data underlying this article can be accessed on Zenodo at DOI: 10.5281/zenodo.806196, and used under the Creative Commons Attribution license.

\section{AUTHOR INFORMATION}

\section{Corresponding Author}

*Phone: +44 0207594 5321. E-mail: j.durrant@imperial.ac.uk. ORCID (0)

Scot Wheeler: 0000-0001-7335-5919

Thomas Kirchartz: 0000-0002-6954-8213

James R. Durrant: 0000-0001-8353-7345

Notes

The authors declare no competing financial interest.

\section{ACKNOWLEDGMENTS}

We acknowledge funding from the Engineering and Physical Sciences Research Council (EPSRC) Projects No. EP/J500021 and EP/I019278, the Supergen programme (EP/J017361/1 and EP/M014797/1) and the Doctoral Training Centre in Science and Application of Plastic Electronic Materials (EP/ G037515), as well as the Welsh Assembly Government Sêr Cymru Solar Project.

\section{REFERENCES}

(1) Saliba, M.; Matsui, T.; Seo, J.-Y.; Domanski, K.; Correa-Baena, J.P.; Nazeeruddin, M. K.; Zakeeruddin, S. M.; Tress, W.; Abate, A.; Hagfeldt, A.; et al. Cesium-Containing Triple Cation Perovskite Solar Cells: Improved Stability, Reproducibility and High Efficiency. Energy Environ. Sci. 2016, 9, 1989-1997. 
(2) Saliba, M.; Orlandi, S.; Matsui, T.; Aghazada, S.; Cavazzini, M.; Correa-Baena, J.-P.; Gao, P.; Scopelliti, R.; Mosconi, E.; Dahmen, K.$\mathrm{H}$;; et al. A Molecularly Engineered Hole-Transporting Material for Efficient Perovskite Solar Cells. Nature Energy 2016, 1, 15017.

(3) Bi, D.; Tress, W.; Dar, M. I.; Gao, P.; Luo, J.; Renevier, C.; Schenk, K.; Abate, A.; Giordano, F.; Correa Baena, J.-P. Efficient Luminescent Solar Cells Based on Tailored Mixed-Cation Perovskites. Sci. Adv. 2016, 2, e1501170.

(4) Jeon, N. J.; Noh, J. H.; Yang, W. S.; Kim, Y. C.; Ryu, S.; Seo, J.; Seok, S. I. Compositional Engineering of Perovskite Materials for High-Performance Solar Cells. Nature 2015, 517, 476-480.

(5) Wu, C.-G.; Chiang, C.-H.; Chang, S. H. A Perovskite Cell with a Record-High- $V_{\text {oc }}$ of $1.61 \mathrm{~V}$ Based on Solvent Annealed $\mathrm{CH}_{3} \mathrm{NH}_{3} \mathrm{PbBr}_{3} / \mathrm{ICBA}$ Active Layer. Nanoscale 2016, 8, 4077-4085.

(6) Ryu, S.; Noh, J. H.; Jeon, N. J.; Chan Kim, Y.; Yang, W. S.; Seo, J.; Seok, S. I. Voltage Output of Efficient Perovskite Solar Cells with High Open-Circuit Voltage and Fill Factor. Energy Environ. Sci. 2014, 7, 2614-2618.

(7) Edri, E.; Kirmayer, S.; Cahen, D.; Hodes, G. High Open-Circuit Voltage Solar Cells Based on Organic-Inorganic Lead Bromide Perovskite. J. Phys. Chem. Lett. 2013, 4, 897-902.

(8) Eperon, G. E.; Stranks, S. D.; Menelaou, C.; Johnston, M. B.; Herz, L. M.; Snaith, H. J. Formamidinium Lead Trihalide: A Broadly Tunable Perovskite for Efficient Planar Heterojunction Solar Cells. Energy Environ. Sci. 2014, 7, 982-988.

(9) Noh, J. H.; Im, S. H.; Heo, J. H.; Mandal, T. N.; Seok, S. I. Chemical Management for Colorful, Efficient, and Stable InorganicOrganic Hybrid Nanostructured Solar Cells. Nano Lett. 2013, 13, 1764-1769.

(10) Correa Baena, J. P.; Steier, L.; Tress, W.; Saliba, M.; Neutzner, S.; Matsui, T.; Giordano, F.; Jacobsson, T. J.; Srimath Kandada, A. R.; Zakeeruddin, S. M.; et al. Highly Efficient Planar Perovskite Solar Cells through Band Alignment Engineering. Energy Environ. Sci. 2015, 8, 2928-2934.

(11) Wehrenfennig, C.; Eperon, G. E.; Johnston, M. B.; Snaith, H. J.; Herz, L. M. High Charge Carrier Mobilities and Lifetimes in Organolead Trihalide Perovskites. Adv. Mater. 2014, 26, 1584-1589.

(12) Wehrenfennig, C.; Liu, M.; Snaith, H. J.; Johnston, M. B.; Herz, L. M. Charge-Carrier Dynamics in Vapour-Deposited Films of the Organolead Halide Perovskite $\mathrm{CH}_{3} \mathrm{NH}_{3} \mathrm{PbI}_{3-\mathrm{x}} \mathrm{Cl}_{\mathrm{x}}$. Energy Environ. Sci. 2014, 7, 2269-2275.

(13) Stranks, S. D.; Eperon, G. E.; Grancini, G.; Menelaou, C.; Alcocer, M. J. P.; Leijtens, T.; Herz, L. M.; Petrozza, A.; Snaith, H. J. Electron-Hole Diffusion Lengths Exceeding 1 Micrometer in an Organometal Trihalide Perovskite Absorber. Science 2013, 342, 341344.

(14) Shi, D.; Adinolfi, V.; Comin, R.; Yuan, M.; Alarousu, E.; Buin, A.; Chen, Y.; Hoogland, S.; Rothenberger, A.; Katsiev, K.; et al. Low Trap-State Density and Long Carrier Diffusion in Organolead Trihalide Perovskite Single Crystals. Science 2015, 347, 519-522.

(15) Credgington, D.; Liu, S.-W.; Nelson, J.; Durrant, J. R. In Situ Measurement of Energy Level Shifts and Recombination Rates in Subphthalocyanine/C60 Bilayer Solar Cells. J. Phys. Chem. C 2014, $118,22858-22864$.

(16) Barnes, P. R. F.; Miettunen, K.; Li, X.; Anderson, A. Y.; Bessho, T.; Gratzel, M.; O’Regan, B. C. Interpretation of Optoelectronic Transient and Charge Extraction Measurements in Dye-Sensitized Solar Cells. Adv. Mater. 2013, 25, 1881-1922.

(17) Foertig, A.; Rauh, J.; Dyakonov, V.; Deibel, C. Shockley Equation Parameters of P3HT:PCBM Solar Cells Determined by Transient Techniques. Phys. Rev. B: Condens. Matter Mater. Phys. 2012, $86,115302$.

(18) O’Regan, B. C.; Barnes, P. R. F.; Li, X.; Law, C.; Palomares, E.; Marin-Beloqui, J. M. Optoelectronic Studies of Methylammonium Lead Iodide Perovskite Solar Cells with Mesoporous $\mathrm{TiO}_{2}$ : Separation of Electronic and Chemical Charge Storage, Understanding Two Recombination Lifetimes, and the Evolution of Band Offsets During J-V Hysteresis. J. Am. Chem. Soc. 2015, 137, 5087-5099.
(19) Shao, Y.; Yuan, Y.; Huang, J. Correlation of Energy Disorder and Open-Circuit Voltage in Hybrid Perovskite Solar Cells. Nature Energy 2016, 1, 15001.

(20) Marin-Beloqui, J. M.; Lanzetta, L.; Palomares, E. Decreasing Charge Losses in Perovskite Solar Cells through $\mathrm{mp}-\mathrm{TiO}_{2} / \mathrm{MAPI}$ Interface Engineering. Chem. Mater. 2016, 28, 207-213.

(21) Marin-Beloqui, J. M.; Hernandez, J. P.; Palomares, E. PhotoInduced Charge Recombination Kinetics in $\mathrm{MAPbI}_{3-\mathrm{x}} \mathrm{Cl}_{\mathrm{x}}$ PerovskiteLike Solar Cells Using Low Band-Gap Polymers as Hole Conductors. Chem. Commun. 2014, 50, 14566-14569.

(22) Carnie, M. J.; Troughton, J.; Regan, B. O.; Barnes, P.; Bryant, D.; Watson, T.; Worsley, D. Identifying Recombination Mechanisms through Materials Development in Perovskite Solar Cells. Presented at the 2015 IEEE 42nd Photovoltaic Specialist Conference (PVSC), New Orleans, LA, Jun 14-19, 2015.

(23) Calado, P.; Telford, A. M.; Bryant, D.; Li, X.; Nelson, J.; O'Regan, B. C.; Barnes, P. R. Evidence for Ion Migration in Hybrid Perovskite Solar Cells with Minimal Hysteresis. Nat. Commun. 2016, 7, 13831.

(24) Bryant, D.; Wheeler, S.; O’Regan, B. C.; Watson, T.; Barnes, P. R. F.; Worsley, D.; Durrant, J. Observable Hysteresis at Low Temperature in "Hysteresis Free" Organic-Inorganic Lead Halide Perovskite Solar Cells. J. Phys. Chem. Lett. 2015, 6, 3190-3194.

(25) van Reenen, S.; Kemerink, M.; Snaith, H. J. Modeling Anomalous Hysteresis in Perovskite Solar Cells. J. Phys. Chem. Lett. 2015, 6, 3808-3814.

(26) Rajagopal, A.; Williams, S. T.; Chueh, C.-C.; Jen, A. K. Y. Abnormal Current-Voltage Hysteresis Induced by Reverse Bias in Organic-Inorganic Hybrid Perovskite Photovoltaics. J. Phys. Chem. Lett. 2016, 7, 995-1003.

(27) McMeekin, D. P.; Sadoughi, G.; Rehman, W.; Eperon, G. E.; Saliba, M.; Hörantner, M. T.; Haghighirad, A.; Sakai, N.; Korte, L.; Rech, B.; et al. A Mixed-Cation Lead Mixed-Halide Perovskite Absorber for Tandem Solar Cells. Science 2016, 351, 151-155.

(28) Suarez, B.; Gonzalez-Pedro, V.; Ripolles, T. S.; Sanchez, R. S.; Otero, L.; Mora-Sero, I. Recombination Study of Combined Halides (Cl, Br, I) Perovskite Solar Cells. J. Phys. Chem. Lett. 2014, 5, 16281635.

(29) Sadhanala, A.; Deschler, F.; Thomas, T. H.; Dutton, S. E.; Goedel, K. C.; Hanusch, F. C.; Lai, M. L.; Steiner, U.; Bein, T.; Docampo, P.; et al. Preparation of Single-Phase Films of $\mathrm{CH}_{3} \mathrm{NH}_{3} \mathrm{~Pb}$ $\left(\mathrm{I}_{1-\mathrm{x}} \mathrm{Br}_{\mathrm{x}}\right)_{3}$ with Sharp Optical Band Edges. J. Phys. Chem. Lett. 2014, 5, 2501-2505.

(30) Schulz, P.; Edri, E.; Kirmayer, S.; Hodes, G.; Cahen, D.; Kahn, A. Interface Energetics in Organo-Metal Halide Perovskite-Based Photovoltaic Cells. Energy Environ. Sci. 2014, 7, 1377-1381.

(31) Seo, J.; Park, S.; Chan Kim, Y.; Jeon, N. J.; Noh, J. H.; Yoon, S. C.; Seok, S. I. Benefits of Very Thin PCBM and LiF Layers for Solution-Processed $\mathrm{p}-\mathrm{i}-\mathrm{n}$ Perovskite Solar Cells. Energy Environ. Sci. 2014, 7, 2642-2646.

(32) Credgington, D.; Durrant, J. R. Insights from Transient Optoelectronic Analyses on the Open-Circuit Voltage of Organic Solar Cells. J. Phys. Chem. Lett. 2012, 3, 1465-1478.

(33) Hoke, E. T.; Slotcavage, D. J.; Dohner, E. R.; Bowring, A. R.; Karunadasa, H. I.; McGehee, M. D. Reversible Photo-Induced Trap Formation in Mixed-Halide Hybrid Perovskites for Photovoltaics. Chemical Science 2015, 6, 613-617.

(34) Cai, B.; Xing, Y.; Yang, Z.; Zhang, W.-H.; Qiu, J. High Performance Hybrid Solar Cells Sensitized by Organolead Halide Perovskites. Energy Environ. Sci. 2013, 6, 1480-1485.

(35) Yoon, S. J.; Draguta, S.; Manser, J. S.; Sharia, O.; Schneider, W. F.; Kuno, M.; Kamat, P. V. Tracking Iodide and Bromide Ion Segregation in Mixed Halide Lead Perovskites During Photoirradiation. ACS Energy Letters 2016, 1, 290-296.

(36) Rehman, W.; Milot, R. L.; Eperon, G. E.; Wehrenfennig, C.; Boland, J. L.; Snaith, H. J.; Johnston, M. B.; Herz, L. M. ChargeCarrier Dynamics and Mobilities in Formamidinium Lead MixedHalide Perovskites. Adv. Mater. 2015, 27, 7938-7944. 
(37) Manser, J. S.; Kamat, P. V. Band Filling with Free Charge Carriers in Organometal Halide Perovskites. Nat. Photonics 2014, 8, 737-743.

(38) Frost, J. M.; Butler, K. T.; Walsh, A. Molecular Ferroelectric Contributions to Anomalous Hysteresis in Hybrid Perovskite Solar Cells. APL Mater. 2014, 2, 081506.

(39) Onoda-Yamamuro, N.; Matsuo, T.; Suga, H. Dielectric Study of $\mathrm{CH}_{3} \mathrm{NH}_{3} \mathrm{PbX}_{3}(\mathrm{X}=\mathrm{Cl}, \mathrm{Br}, \mathrm{I})$. J. Phys. Chem. Solids 1992, 53, 935-939.

(40) O’Regan, B. C.; Bakker, K.; Kroeze, J.; Smit, H.; Sommeling, P.; Durrant, J. R. Measuring Charge Transport from Transient Photovoltage Rise Times. A New Tool to Investigate Electron Transport in Nanoparticle Films. J. Phys. Chem. B 2006, 110, 17155-17160.

(41) Garcia-Belmonte, G.; Munar, A.; Barea, E. M.; Bisquert, J.; Ugarte, I.; Pacios, R. Charge Carrier Mobility and Lifetime of Organic Bulk Heterojunctions Analyzed by Impedance Spectroscopy. Org. Electron. 2008, 9, 847-851.

(42) Foster, S.; Deledalle, F.; Mitani, A.; Kimura, T.; Kim, K.-B.; Okachi, T.; Kirchartz, T.; Oguma, J.; Miyake, K.; Durrant, J. R. Electron Collection as a Limit to Polymer:PCBM Solar Cell Efficiency: Effect of Blend Microstructure on Carrier Mobility and Device Performance in PTB7:PCBM. Adv. Energy Mater. 2014, 4, 1400311.

(43) Wheeler, S.; Deledalle, F.; Tokmoldin, N.; Kirchartz, T.; Nelson, J.; Durrant, J. R. Influence of Surface Recombination on ChargeCarrier Kinetics in Organic Bulk Heterojunction Solar Cells with Nickel Oxide Interlayers. Phys. Rev. Appl. 2015, 4, 024020.

(44) Foertig, A.; Kniepert, J.; Gluecker, M.; Brenner, T.; Dyakonov, V.; Neher, D.; Deibel, C. Nongeminate and Geminate Recombination in PTB7:PCBM Solar Cells. Adv. Funct. Mater. 2014, 24, 1306-1311.

(45) Kirchartz, T.; Nelson, J. Meaning of Reaction Orders in Polymer:Fullerene Solar Cells. Phys. Rev. B: Condens. Matter Mater. Phys. 2012, 86, 165201.

(46) Deledalle, F.; Shakya Tuladhar, P.; Nelson, J.; Durrant, J. R.; Kirchartz, T. Understanding the Apparent Charge Density Dependence of Mobility and Lifetime in Organic Bulk Heterojunction Solar Cells. J. Phys. Chem. C 2014, 118, 8837-8842.

(47) Kirchartz, T.; Deledalle, F.; Tuladhar, P. S.; Durrant, J. R.; Nelson, J. On the Differences between Dark and Light Ideality Factor in Polymer:Fullerene Solar Cells. J. Phys. Chem. Lett. 2013, 4, 23712376.

(48) Kirchartz, T.; Pieters, B. E.; Kirkpatrick, J.; Rau, U.; Nelson, J. Recombination Via Tail States in Polythiophene:Fullerene Solar Cells. Phys. Rev. B: Condens. Matter Mater. Phys. 2011, 83, 115209.

(49) Marinova, N.; Tress, W.; Humphry-Baker, R.; Dar, M. I.; Bojinov, V.; Zakeeruddin, S. M.; Nazeeruddin, M. K.; Grätzel, M. Light Harvesting and Charge Recombination in $\mathrm{CH}_{3} \mathrm{NH}_{3} \mathrm{PbI}_{3}$ Perovskite Solar Cells Studied by Hole Transport Layer Thickness Variation. ACS Nano 2015, 9, 4200-4209.

(50) Pockett, A.; Eperon, G. E.; Peltola, T.; Snaith, H. J.; Walker, A.; Peter, L. M.; Cameron, P. J. Characterization of Planar Lead Halide Perovskite Solar Cells by Impedance Spectroscopy, Open-Circuit Photovoltage Decay, and Intensity-Modulated Photovoltage/Photocurrent Spectroscopy. J. Phys. Chem. C 2015, 119, 3456-3465.

(51) Yao, J.; Kirchartz, T.; Vezie, M. S.; Faist, M. A.; Gong, W.; He, Z.; Wu, H.; Troughton, J.; Watson, T.; Bryant, D.; Nelson, J. Quantifying Losses in Open-Circuit Voltage in Solution-Processable Solar Cells. Phys. Rev. Appl. 2015, 4, 014020.

(52) Tress, W.; Marinova, N.; Inganas, O.; Nazeeruddin, M. K.; Zakeeruddin, S. M.; Graetzel, M. Predicting the Open-Circuit Voltage of $\mathrm{CH}_{3} \mathrm{NH}_{3} \mathrm{PbI}_{3}$ Perovskite Solar Cells Using Electroluminescence and Photovoltaic Quantum Efficiency Spectra: The Role of Radiative and Non-Radiative Recombination. Adv. Energy Mater. 2015, 5, 1400812.

(53) De Wolf, S.; Holovsky, J.; Moon, S.-J.; Löper, P.; Niesen, B.; Ledinsky, M.; Haug, F.-J.; Yum, J.-H.; Ballif, C. Organometallic Halide Perovskites: Sharp Optical Absorption Edge and Its Relation to Photovoltaic Performance. J. Phys. Chem. Lett. 2014, 5, 1035-1039.

(54) Leguy, A. M. A.; Azarhoosh, P.; Alonso, M. I.; Campoy-Quiles, M.; Weber, O. J.; Yao, J.; Bryant, D.; Weller, M. T.; Nelson, J.; Walsh, A.; et al. Experimental and Theoretical Optical Properties of
Methylammonium Lead Halide Perovskites. Nanoscale 2016, 8 , 6317-6327.

(55) Paulke, A.; Stranks, S. D.; Kniepert, J.; Kurpiers, J.; Wolff, C. M.; Schön, N.; Snaith, H. J.; Brenner, T. J. K.; Neher, D. Charge Carrier Recombination Dynamics in Perovskite and Polymer Solar Cells. Appl. Phys. Lett. 2016, 108, 113505.

(56) Schäfer, S.; Petersen, A.; Wagner, T. A.; Kniprath, R.; Lingenfelser, D.; Zen, A.; Kirchartz, T.; Zimmermann, B.; Würfel, U.; Feng, X.; Mayer, T. Influence of the Indium Tin Oxide/Organic Interface on Open-Circuit Voltage, Recombination, and Cell Degradation in Organic Small-Molecule Solar Cells. Phys. Rev. B: Condens. Matter Mater. Phys. 2011, 83, 165311. 